\title{
Effects of Process Variables on Poly-Aluminum Chloride (PAC)-Rosin Sizing Performance under Neutral Papermaking Conditions
}

\author{
Yahya Hamzeh, ${ }^{*}{ }^{\dagger}$ Mohammad Hassan Ekhtera, ${ }^{\dagger}$ Martin A. Hubbe, ${ }^{\dagger}$ Soheila Izadyar, ${ }^{\dagger}$ and \\ Kambiz Pourtahmasi ${ }^{\dagger}$ \\ Department of Wood and Paper Sciences and Technology, Faculty of Natural Resources, University of Tehran, \\ P.O. Box 31585-4313, Karaj-Iran, and Department of Forest Biomaterials Science and Engineering, North \\ Carolina State University, Campus Box 8005, Raleigh, North Carolina 27695-8005
}

The effects of process variables, including poly-aluminum chloride (PAC) and rosin levels and equilibration time on PAC-rosin sizing performance, were investigated for three alternative sizing processes, include conventional, reverse sizing, and premixing under neutral papermaking conditions. The individual and interaction effects of sizing variables were determined. It was found that, in contrast to conventional sizing, the sizing efficiency increased with increasing equilibration time when reverse and premixing processes were used for the sizing treatment. In both processes, increasing equilibration time can lead to potential savings in PAC or rosin. Finally, the optimum conditions for more cost-effective sizing were determined for the three sizing processes.

\section{Introduction}

Paper strength properties depend considerably on hydrogen bonding between cellulose fibers. The penetration of water into the paper structure and fibers can break hydrogen bonds and greatly weaken the paper. To avoid this limitation and to increase the water-repellency of paper, hydrophobic sizing is performed for most paper grades, especially in the case of writing and packaging papers. For several reasons, e.g., easy control of sizing, simple handling of rosin, compatibility with other additives and cost effectiveness, generally acidic alum-rosin sizing methods have been applied for paper sizing since the early 1800 s. $^{1}$

Since the late 1980 s, due to considerable advantages, e.g., superior strength properties, higher durability of the obtained paper, less corrosion in papermaking machinery, and greater use of inexpensive calcium carbonate, a large proportion of papermaking systems has been transformed to neutral-alkaline papermaking conditions, and in parallel, the use of acidic alum-rosin sizing has decreased. ${ }^{2}$ Under neutral-alkaline papermaking conditions, alum tends to be converted to neutral aluminum floc, $\mathrm{Al}(\mathrm{OH})_{3}$, which is not an effective species for retaining rosin particle on fiber surfaces. Under neutral-alkaline conditions, internal sizing is done principally using synthetic sizing agents such as alkyl ketene dimer (AKD) or alkenyl succinic anhydride (ASA). However, despite their advantages, e.g., operating without alum and giving sufficient sizing degrees to paper at low addition levels, some problems such as the low friction coefficient of AKD-sized papers, size reversion, deposit formation on the paper machine and press felts, relatively high costs, and insufficient machine sizing effect in paper have been associated with the use of synthetic sizing agents. ${ }^{3,4}$ Due to the several advantages of rosin sizing in papermaking, the technical teams in many papermaking mills want to move into neutral-alkaline $\mathrm{pH}$ papermaking systems without abandoning the use of rosin-based sizing.

Numerous investigations carried out by different research groups to develop new sizing agents or special sizing processes

* To whom correspondence should be addressed. Tel/Fax: (+98) 261-2249311. E-mail: hamzeh@ut.ac.ir.

University of Tehran.

North Carolina State University. for efficient application of rosin size under neutral-alkaline papermaking conditions. A review of internal sizing research was published recently by Hubbe. ${ }^{5}$ Various authors have studied esterification between the carboxylic groups of rosin and the hydroxyl groups on the fiber surfaces. However, because such ester bonding requires temperatures higher than those usually prevailing in paper machine dryer systems, such ester formation is not usually expected to play a significant role in rosin anchoring to fiber surfaces. ${ }^{5,6}$ Alternatively, some researchers have investigated sizing strategies with esterified rosins. ${ }^{3,5,7,8}$ The esterified rosins, by themselves, show almost no sizing effect, and their effective use requires that some rosin molecules are already bound on the fiber's surface, and these initial rosin molecules hold the unbound rosin molecules by hydrophobic association. ${ }^{5,9}$ Other authors have attempted to find chemicals that are able to act as mordants for rosin sizing. ${ }^{2}$ For instance, many alternative chemicals such as polyethylenimine, ${ }^{10}$ linear polyamines, ${ }^{11}$ and low-charge-density cationic amines ${ }^{12}$ have been studied, but none of them have achieved widespread industrial application.

Previous studies showed that poly-aluminum chlorides (PAC) offer an alternative to alum because they are capable of delivering cationic aluminum species at elevated $\mathrm{pH}$ (e.g., $5-7.5)$ to retain and fix the rosin on the fiber surfaces. ${ }^{2,4,13}$ PAC does not hydrolyze as quickly as alum, and thus it can maintain cationic charges up to neutral-alkaline $\mathrm{pH}$ values. ${ }^{13}$ Recent studies have shown that efficient rosin sizing could be achieved under neutral conditions by the premixing of alum with rosin and the addition of the mixture to the pulp suspension. ${ }^{1,2,14}$ Relative to the importance of possible application of this strategy in papermaking, little published work has related to optimal technological conditions for this potentially highly efficient sizing process.

In this study, the sizing efficiency of recycled old corrugated container (OCC) paper was investigated for three different types of PAC/rosin sizing processes, including conventional sizing, reverse sizing (i.e., adding the aluminum chemical before the rosin product), and premixing. Independent variables included the levels of PAC and rosin, the equilibration time between adding of PAC and rosin in conventional and reverse sizing, and premixing time prior to adding the mixture of rosin/PAC 
to the pulp furnish. The results may increase our knowledge to optimize process conditions for highly efficient, cost-effective sizing, particularly in cases where the premixing processes is being considered.

\section{Material and Methods}

2.1. Materials. The recycled OCC samples used in this research were collected from wastepaper supplies that were received at the Iran Wood and Paper Mill Co. (Ltd.) in the northeast of Iran. After repulping and washing, the obtained pulps were beaten with a PFI-MILL NO. 227 beater to $350 \mathrm{~mL}$ CSF according to the T227 OM-99 TAPPI test method. Fortified dispersed rosin $(50 \%$ solid content, supplied by Sobra Co. Ltd., Iran) at the three levels of $0.1,0.2$, and 0.4 based on dry pulp was used. This product consists essentially of dispersed acid rosin, which has been stabilized by casein. The poly-aluminum chloride (PAC) was obtained from Falizan Co., Ltd., Iran, and it contains an equivalent of $29 \% \mathrm{Al}_{2} \mathrm{O}_{3}$ with basicity of $75 \%$. The amounts of PAC were varied in four levels $(0.05,0.1,0.2$, and $0.4 \%$ ) based on the dry pulp. The hardness of fresh water that is used in the mentioned paper mill was determined according to Standard Method 122 BEDTA. The hardness value obtained was 110 ppm $\mathrm{CaCO}_{3}$.

2.2. Handsheet Making and Cobb Size Measurement. Pulp suspensions with $0.15 \%$ consistency were prepared with fresh water (hardness $110 \mathrm{ppm} \mathrm{CaCO}_{3}$ ) at $25^{\circ} \mathrm{C}$, and the $\mathrm{pH}$ was adjusted in the range of 7.0-7.2 using $\mathrm{H}_{2} \mathrm{SO}_{4}$ or $\mathrm{NaOH}$ of 0.02 $\mathrm{mol} / \mathrm{L}$.

In conventional sizing, a known amount of rosin was added first to the pulp suspension. After stirring the pulp suspension for a desired equilibration of time in six levels (10, 60, 900, $1800,2700,3600 \mathrm{~s}$ ), the PAC was added, with continued stirring.

In reverse sizing, known amounts of PAC were first added to the pulp suspension. After stirring of the pulp suspension for a desired equilibration of time in six levels $(10,60,900$, $1800,2700,3600 \mathrm{~s}$ ), the rosin was added with continued stirring.

In the premixing procedure, known amounts of PAC and rosin were added to $1 \mathrm{~L}$ of tap water and mixed in a high-shear blender ( $3500 \mathrm{rpm})$ for a desired equilibration of time, and then the mixture was added to the pulp suspension at an adjusted $\mathrm{pH}$ of 7.

In all the above cases, after $10 \mathrm{~s}$ of stirring, the suspension was used for the preparation of $120 \mathrm{~g} / \mathrm{m}^{2}$ handsheets. The formed handsheets were pressed first at $60 \mathrm{kPa}$ for $20 \mathrm{~s}$ and then at $300 \mathrm{kPa}$ for $5 \mathrm{~min}$ and were dried at ambient temperature for $24 \mathrm{~h}$. The water absorption of handsheets (Cobb test) was determined using the T441 OM-98 TAPPI test method. The sizing degrees were determined without curing treatment in dryer. The indicated results are the average of five trials. Lower values of Cobb sizing indicate greater resistance to water penetration.

2.3. Experimental Design. The experimental results were fitted to the following first-order equation as a multiple linear regression,

$$
Z=a+b X_{\mathrm{P}}+c X_{\mathrm{R}}+d X_{\mathrm{T}}+e X_{\mathrm{P}} X_{\mathrm{R}}+f X_{\mathrm{P}} X_{\mathrm{T}}+g X_{\mathrm{R}} X_{\mathrm{T}}
$$

where $Z$ denotes the response variable (Cobb size), $X_{P}, X_{\mathrm{R}}$, and $X_{\mathrm{T}}$ the normalized values of PAC, rosin, and equilibration time levels, and letters $a-g$ denote constants.

The values of the independent variables were normalized from -1 to $+1 \quad(-1$ refers to $0.2 \%$ rosin, $0 \% \mathrm{PAC}$, and $0 \mathrm{~s}$ equilibration time while +1 states refer to $0.4 \%$ rosin, $0.4 \%$ $\mathrm{PAC}$, and $3600 \mathrm{~s}$ equilibration time) by using eq 2 in order to facilitate direct comparison of the resulting equation coefficients and understanding of the effects of the individual variables on the dependent response considered (Cobb size or freeness):

$$
X_{n}=2 \frac{X-X_{\text {mean }}}{X_{\max }-X_{\min }}
$$

In this equation $X_{n}$ is the normalized value of PAC, rosin, or equilibration time; $X$ is the absolute experimental value of the variable concerned; $X_{\text {mean }}$ is the mean of the extreme values of $X$; and $X_{\max }$ and $X_{\min }$ are the maximum and minimum values of each variable, respectively. This normalization results in a more accurate estimation of the regression coefficients. Table 1 shows the absolute and normalized values of the operational variables used in this study.

The values of responses obtained allow the calculation of mathematical estimation models for each response, which were subsequently used to characterize the individual and interaction effects of variables. The statistical software MINITAB (version 14) of Minitab, Inc., USA was used to conduct a multiple linear regression analysis involving all the terms of eq 1.

\section{Results and Discussion}

3.1. Regression Equations. The data processing of sizing response of the obtained handsheets under the specified conditions resulted in the following equations (eqs 3-5) for each sizing process. These equations indicate the individual effects of various parameters as well as their interactions with other variables on the Cobb size values of handsheet. The individual effect of each variable estimates its average effect over all possible conditions of the other variables. This means that the individual effect indicates the general trend of sizing performance as a function of each variable.

Conventional sizing (first rosin and later PAC) with desired equilibration time:

$$
\text { Cobb test }_{120}=95.5-22.3 X_{\mathrm{P}}-12.0 X_{\mathrm{R}}-8.5 X_{\mathrm{PR}}+1.8 X_{\mathrm{RT}}
$$

Reverse sizing (first PAC and later rosin) with desired equilibration time:

$$
\text { Cobb test }_{120}=88.3-22.0 X_{\mathrm{P}}-12.5 X_{\mathrm{R}}-9.1 X_{\mathrm{PR}}-1.45 X_{\mathrm{T}}
$$

Premixing sizing with desired mixing time of rosin and PAC:

$$
\text { Cobb test }_{120}=86.2-21.5 X_{\mathrm{P}}-13.1 X_{\mathrm{R}}-7.9 X_{\mathrm{PR}}-3 X_{\mathrm{T}}
$$

From these equations, it is clear that the PAC level was the most significant variable in each of the sizing processes. In all processes, the individual effect of rosin level and its interaction effect with PAC level were significant, but they were less important. In conventional sizing, the interaction effect of rosin level and equilibration time was significant. In reverse and premixing sizing, the individual effects of equilibration time were significant.

3.2. Individual Effects. The various effects of the operating variables can be shown graphically. Figure 1 presents the individual effects of PAC on the Cobb size for the three sizing procedures. The Cobb size value of unsized paper was 140 $\mathrm{g} / \mathrm{m}^{2} / 2 \mathrm{~min}$. 
4304 Ind. Eng. Chem. Res., Vol. 47, No. 13, 2008

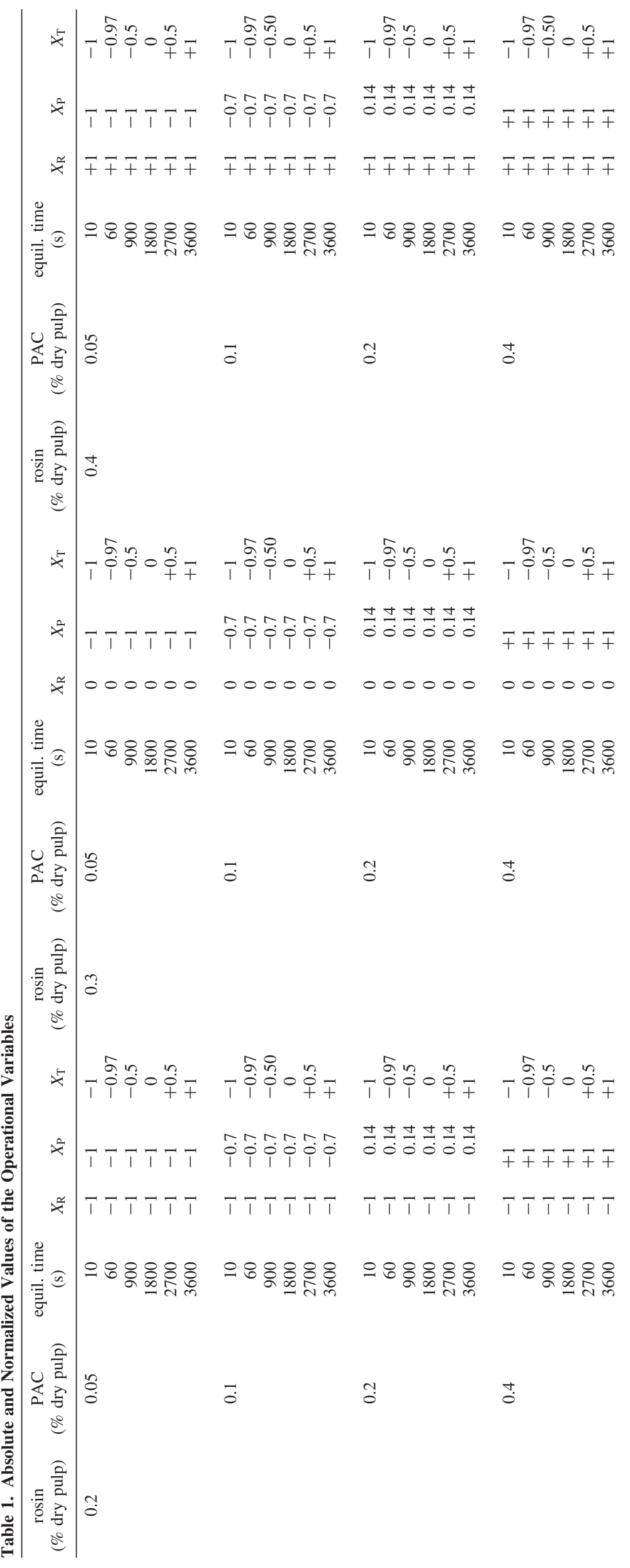




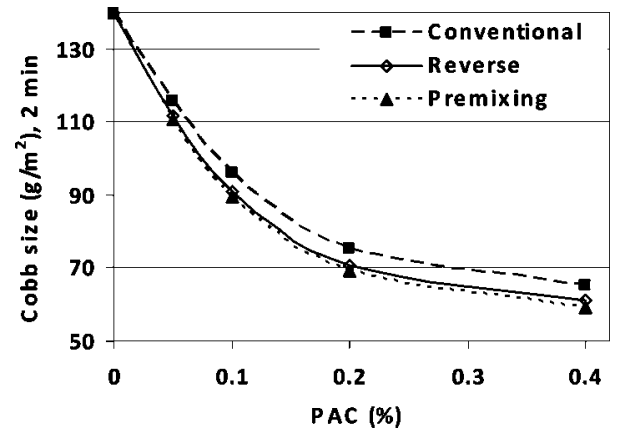

Figure 1. Individual effect of PAC level on the Cobb size in three sizing procedure.

Figure 1 shows that at a given PAC level, the lowest Cobb size test result was obtained by premixing, indicating the highest level of sizing. This was followed closely by reverse sizing, the results for which were not statistically different from those for premixing under the conditions of testing. Conventional sizing yielded the lowest effectiveness, though still within a few $\mathrm{g} / \mathrm{m}^{2}$ of the other values at a given level of PAC treatment. Globally, when the PAC level increased from 0 to $0.4 \%$ (on dry weight of pulp), the sizing degree increased in a nonlinear manner. The pattern of the sizing response versus PAC level indicates that at a lower level of PAC, the cationic species of PAC adsorbed very rapidly on the fiber surfaces, providing a linear decrease in the Cobb sizing values. As the PAC level increased from 0.2 to $0.4 \%$, the incremental change in Cobb values decreased. The results are assumed to be a consequence of the limited availability of anionic carboxylic groups on the fiber surfaces to react with aluminums ions $\left(\mathrm{Al}^{3+}\right.$ as well as aluminum polymers) to form cationic sites that form electrostatic (ionic) or coordination complexes with the relatively large rosin particles (about $0.1 \mu \mathrm{m}$ in diameter). As PAC dosage increased from 0.2 to $0.4 \%$, the relative availability of carboxylic groups decreased, and the sizing development trend decreased. The important effect of carboxylic groups on the fibers surfaces on the sizing efficiency have been reported by Kitaoka et al. ${ }^{15,16}$ and Parks. ${ }^{17}$

The small difference between the responses of premixing and reverse sizing confirms that the interaction between cationic aluminum species with carboxyl groups on the fiber surfaces is relatively rapid and occurred during the $10 \mathrm{~s}$ of stirring before handsheet formation in both processes. It makes logical sense to expect an advantage in the case of premixing, due to the fact that the initial interaction between the aluminum product and the carboxylate groups of rosin is able to take place under weakly acidic $\mathrm{pH}$ conditions that favor the existence of oligomeric ionic aluminum species. One can expect a greater degree of hydrolysis of aluminum to neutral $\mathrm{Al}(\mathrm{OH})_{3}$ floc before interaction with rosin when using either the conventional or reverse sizing systems in weakly alkaline process conditions. However, when using a rosin emulsion product, as in the present work, only a minor part of the rosin is expected to be present in its dissociated, carboxylate form. This fact may help explain why there was only a minor advantage in the case of premixing.

Figure 2 shows the individual effect of rosin level on the Cobb size test results. Similarly to the individual effect of PAC, the lowest Cobb test was obtained by premixing, followed by reverse sizing, and conventional sizing was by far the least effective.

The sizing degree in rosin sizing is mainly governed by size content in the paper, and theoretically $0.2 \mathrm{mg} / \mathrm{g}(0.1-0.2 \%$ rosin based on dry pulp) rosin content on paper sheet could be

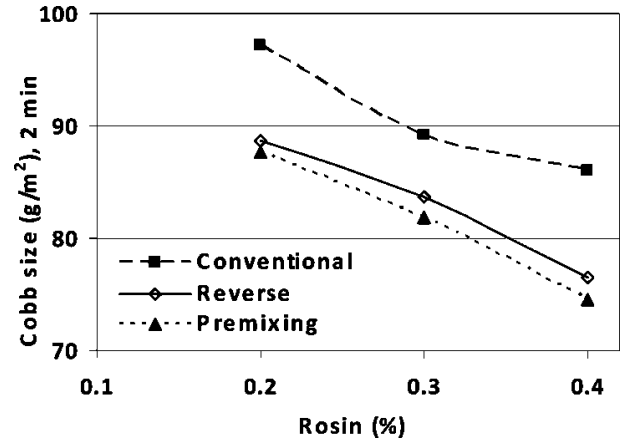

Figure 2. Individual effect of rosin level on the Cobb size in three sizing system.

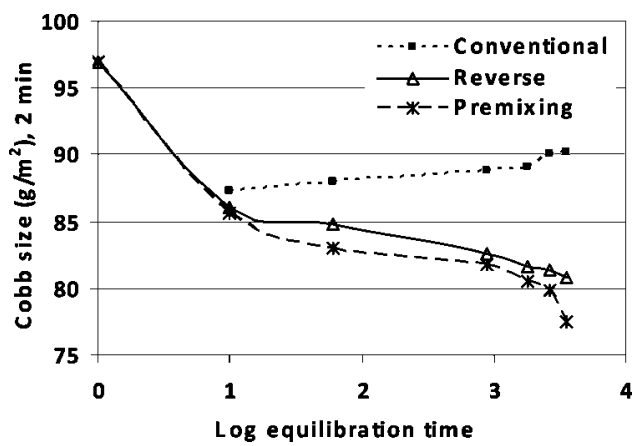

Figure 3. Individual effect of equilibration time on the Cobb size in three sizing system.

expected to give effective sizing. ${ }^{3}$ The dispersed rosin retention is globally governed by interaction between rosin particles and cationic species (aluminum species or cationic retention aids applied for stabilizing dispersed rosin) that initially retained on the fibers surfaces. ${ }^{5,18}$ Insufficient sizing at $0.2 \%$ rosin dosage indicates that the applied rosin was not completely retained on the pulp surface because of ineffective interactions between rosin particles and cationic sites on the fibers. Increasing the rosin dosage increased the probability of interaction between rosin particles and cationic sites on the fiber surfaces that led to greater sizing degree.

In conventional sizing, higher levels of rosin offer a greater proportion of ineffective interactions between calcium cations and decrease the sizing performance to a greater degree.

Figure 3 shows the individual effect of equilibration time on sizing development. The first observation is that in the three sizing systems, an equilibration time of $10 \mathrm{~s}$ caused a significant increase in paper sizing relative to no equilibration. This indicates that the aluminum cations adsorption on the pulp fiber surfaces occurred rapidly, followed by rapid absorption of rosin onto the created cationic sites.

The results showed that during conventional sizing increasing the equilibration time was unfavorable for PAC-rosin sizing. The higher the equilibration time, the higher would be the expected interaction between rosin particles and calcium ions, leading to lower sizing performance. On the other hand, in reverse and premixing sizing, increasing equilibration time was favorable for PAC-rosin sizing. The positive effect of equilibration time was more significant in premixing sizing.

The effect of equilibration time on the reverse and premixing sizing response has not been explored in previous work. The positive effect of increasing equilibration time can be explained in terms of the interaction among hydrolyzed aluminum species. Gao et al. reported that increasing the mixing time of PAC solution from 0 to 20 min caused an increasing mean size of 


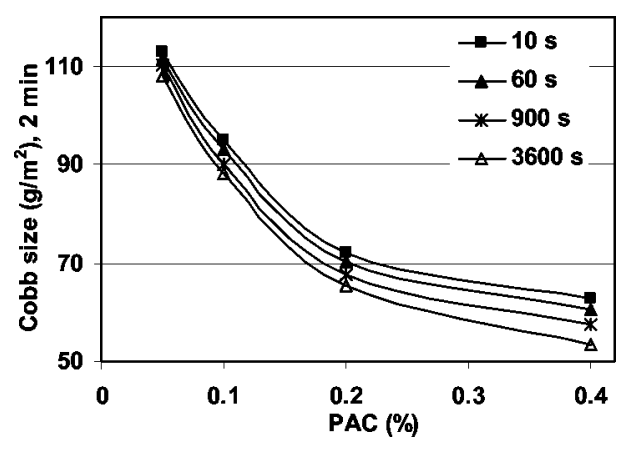

Figure 4. Effect of mixing time and PAC level on Cobb size at a given rosin level $(0.3 \%)$ in premixing sizing.

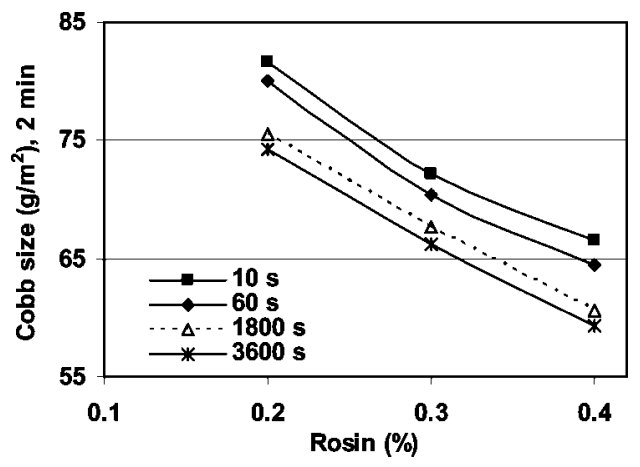

Figure 5. Effect of mixing time and rosin level on Cobb size at a given PAC level $(0.2 \%)$ in premixing sizing.

polyaluminum species. ${ }^{19}$ Generally, the larger species can be expected to adsorb more strongly on fiber surfaces. This would be expected to lead to higher retention of rosin particles on paper and higher sizing efficiency. In the case of premixing, higher sizing efficiency can be explained with both polymerization of polyaluminum species as well as with some preliminary reaction between aluminum species and the saponified portion of the rosin to form aluminum rosinate only on the surface of rosin particles. $^{20}$ Zou et al. reported some small modification in the size distribution of rosin particles after premixing. ${ }^{1}$

It has been shown that the positive effect of premixing depends on the several factors, such as the alum to rosin ratio, furnish hardness, and premixing concentration. ${ }^{1,2,14}$ In addition to these factors, our results showed a significant positive effect of increasing premixing time on the sizing efficiency. Moreover, as shown in Figure 4, the positive effect of mixing time in premixing sizing depended on the applied PAC level. At a given rosin level, increasing the mixing time decreased the Cobb test results at all levels of PAC dosage. As the PAC level increased, the effect of mixing time increased. As seen in Figure 4, the Cobb test obtained with a mixing time of $3600 \mathrm{~s}, 0.3 \%$ rosin, and $0.2 \%$ PAC was similar to the Cobb test that was obtained with a mixing time of $60 \mathrm{~s}, 0.3 \%$ rosin, and $0.4 \%$ PAC. This means that increasing the mixing time led to a significant savings in PAC consumption. Similarly, this was true for rosin saving at any given PAC level (Figure 5). A similar effect of mixing time was observed to a lesser degree in the case of reverse sizing.

3.3. Interaction Effects. In the previous section, it was shown that the individual increase of either the PAC or rosin level had a limited effect on water absorption. Equations 3-5 show that there are significant interactions between rosin and PAC levels in the three sizing systems. At lower levels of PAC, increasing rosin dosage did not affect Cobb size (Figure 6). This indicated that $0.05 \%$ PAC was not sufficient for the anchoring

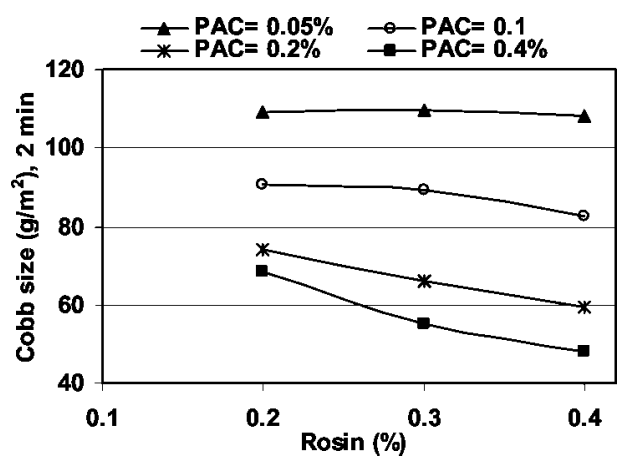

Figure 6. Interaction effect of PAC and rosin levels on the Cobb size in premixing sizing (mixing time $3600 \mathrm{~s}$ ).

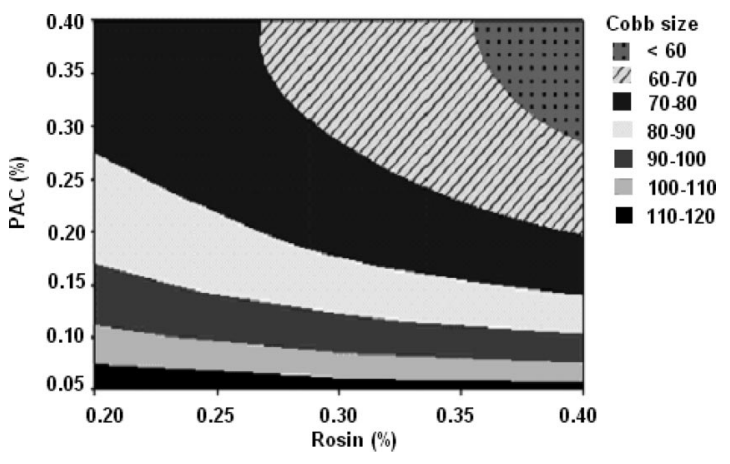

Figure 7. Contour plot diagram of rosin level-PAC level on Cobb size (conventional sizing).

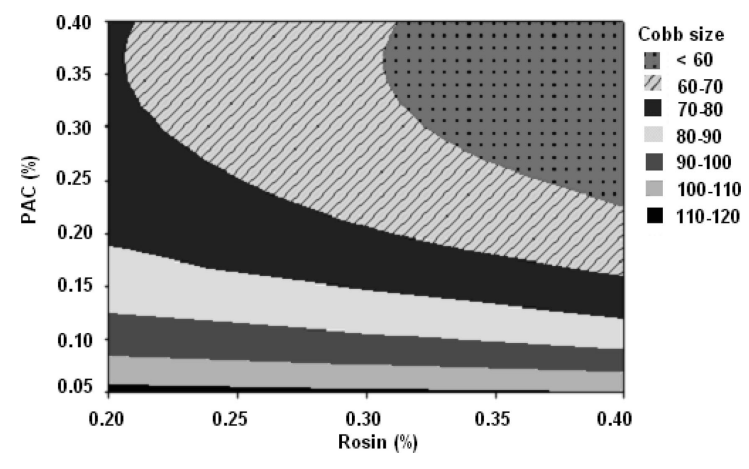

Figure 8. Contour plot diagram of rosin level-PAC level on Cobb size (reverse sizing).

of additional rosin to the fiber surfaces. Approximately the same trend could be seen at $0.1 \%$ PAC. However, when $0.2 \%$ PAC was applied, the trend of sizing performance changed, and higher rosin application led to lower Cobb sizing values. This indicates that the sizing of paper with PAC and rosin required a certain level of positive charge on the fiber surfaces to retain and orient rosin size particles. As indicated in eqs 3-5, a significant interaction of PAC and rosin levels was obtained in conventional, reverse, and premixing process.

3.4. Optimization of Process Variables. The effect of the sizing process on size development is shown in Figures 7-9. Regardless of the equilibration time effect, it is clear that under the given conditions of PAC and rosin level, the premixing process resulted in lower Cobb test results. In conventional processing the optimum ratio of PAC to rosin varied from 0.75 , when at least $0.4 \%$ rosin was applied, to 1.14 when $0.35 \%$ rosin was applied. The application of $0.4 \%$ rosin and $0.3 \%$ PAC (ratio 0.75 ) appeared to be more cost-effective. In reverse sizing, the optimum ratio of PAC to rosin varied from 0.6 when at least $0.4 \%$ rosin was applied, to 1.15 when $0.3 \%$ rosin was applied. 


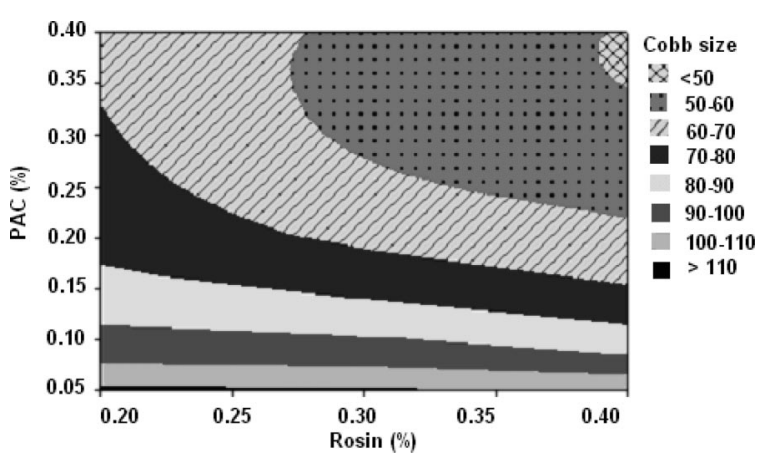

Figure 9. Contour plot diagram of rosin level-PAC level on Cobb size (premixing sizing).

This means that the application of $0.4 \%$ rosin and $0.24 \%$ PAC was sufficient for desired sizing.

In premixing sizing, the optimum ratio of PAC to rosin varied from 0.55 to 1.30 . Therefore, with premixing sizing, lower amounts of aluminum compounds were required. Zou et al. reported the optimum PAC to rosin ratio was 1 for $1 \%$ rosin application. ${ }^{2}$ Our results showed that this ratio depended on the rosin level application, and it can be optimized to obtain costeffective, efficient sizing.

During conventional sizing, the equilibration time between addition of the sizing agent and the aluminum product must to be as short as possible. In reverse and premixing sizing, the best size development of sizing occurred with a higher equilibration time. As indicated above, at a higher equilibration time, savings of rosin or PAC were achieved.

\section{Conclusions}

This study has confirmed previous results indicating greater efficiency in the case of premixing sizing when using a dispersed rosin sizing agent under neutral to alkaline papermaking conditions. However, the effect of equilibration time on the sizing effect was opposite to that of conventional sizing. The results are consistent with a mechanism of size retention that is principally governed by rosin particles interacting with soluble aluminum species, giving a positive charge so that the rosin precipitates onto fiber surfaces. In the case of reverse sizing, the PAC absorbs on the fiber surfaces creating positive sites of anchoring of rosin emulsion particles. The efficiency of sizing process could be increased by the optimization of process variables. In this study, the optimum values of PAC to rosin ratio and equilibration time to obtain efficient and cost-effective sizing were determined for three different sizing procedures.

\section{Acknowledgment}

This study was financially supported by the Research Deputy of the University of Tehran. The authors gratefully acknowledge support from the Iran Wood and Paper Mill Co., Sobra Co., Ltd., Iran, and the Falizan Co., Ltd., Iran.

\section{Literature Cited}

(1) Zou, Y.; Hsieh, J. S.; Wang, T. S.; Mehnert, E.; Kokoszka, J. The Mechanism of Premixing Rosin Sizes for Neutral-Alkaline Papermaking. Tappi J. 2004, 3 (9), 16.

(2) Zou, Y.; Hsieh, J. S.; Wang, T. S.; Mehnert, E.; and Kokoszka, J. Rosin Sizing under Neutral-Alkaline Papermaking Conditions. Tappi J. 2003, 3 (7), E41.

(3) Ito, K.; Isogai, A.; Onabe, F. Rosin-Ester Sizing of Alkaline Papermaking. J. Pulp Pap. Sci. 1999, 25 (6), 222.

(4) Liu, J. Sizing with Rosin and Alum at Neutral pH. Pap. Technol. (Bury, U.K.) 1993, 34 (8), 20.

(5) Hubbe, M. Paper's Resistance to Wetting-a Review of Internal Sizing Chemicals and Their Effects. BioResources 2007, 2 (1), 106.

(6) Zhuang, J.; Chen, M.; Biermann, C. J. Rosin Soap Sizing Without Mordants by Immersion in Size Solution. Tappi J. 1997, 80 (1), 271.

(7) Liu, Y.; Niu, M. ; Zhang, Y. The Research of Rosin Ester Neutral Sizing Agent. Proc. 2nd ISTPPBFP, (2004) Oct. 13-14, 2004, Nanjing Forestry University, China, pp 441-443..

(8) Nitzman, A. F.; Royappa, A. T. Sizing Variations of Dispersed Rosin Sizes with Fortification, Hardness, pH, and Temperature. Tappi J. 2003, 2 (4), 8.

(9) Wang, F.; Wu, Z.; Tanaka, H. Preparation and Sizing Mechanisms of Neutral Rosin Size 2: Functions of Rosin Derivatives on Sizing Efficiency. J. Wood Sci. 1999, 45, 475.

(10) Hartong, B.; Deng, Y. Evidence of Ester Bond Contribution to Neutral to Alkaline Rosin Sizing using Polyethylenimine-Epichlorohydrin as a Mordant. J. Pulp Pap. Sci. 2004, 30 (7), 203.

(11) Wu, Z.-H.; Chen, S.-P.; Tanaka, H. Effects of Polyamine Structure on Rosin Sizing under Neutral Papermaking Conditions. J. Appl. Polym. Sci. 1997, 65 (11), 2159.

(12) Wang, F.; Tanaka, H. Mechanisms of Neutral-Alkaline Paper Sizing with Usual Rosin Size Using Alum-Polymer Dual Retention Aid System. J. Pulp Pap. Sci. 2001, 27 (1), 8.

(13) Isolati, A. The Use of Aluminum Polychloride for Internal Rosin Sizing of Paper. Рар. Рии 1989, 66 (9), 521.

(14) Katz, G.; House, L. W.; Alexander, D. E. Internal Paper Sizing Improvements. U.S. Patent 6540877, 2003.

(15) Kitaoka, T.; Isogai, A.; Onabe, F. Sizing Mechanism of Emulsion Rosin Size-Alum Systems. Part 1. Relationships between Sizing Degrees and Rosin Size or Aluminum Content in Rosin-Sized Handsheets. Nordic Pulp Pap. Res. J. 1995, 10 (4), 253.

(16) Kitaoka, T.; Isogai, A; Onabe, F. Sizing Mechanism of Emulsion Rosin Size Alum Systems. Part 2. Structures of Rosin Size Components in the Paper Sheet. Nordic Pulp Paper Res. J. 1997, 12 (1), 26.

(17) Parks, E. J.; Hebert, R. L. Thermal Analysis of Ion Exchange Reaction Products of Wood Pulps with Calcium and Aluminum Cation. Tappi J. 1972, 55, 1510.

(18) Marton, J. Fundamental Aspects of the Rosin Sizing Process: Mechanistic Differences between Acid and Soap Sizing. Nordic Pulp Pap. Res. J. 1989, 4, 77.

(19) Gao, B. Y.; Hahn, H. H.; Hoffmann, E. Evaluation of AluminumSilicate Polymer Composite As a Coagulant for Water Treatment. Water Res. 2002, 36, 3573.

(20) Strazdins, E. Mechanistic Aspects of Rosin Sizing. Tappi J. 1977, $60(10), 102$.

Received for review January 20, 2008 Revised manuscript received March 7, 2008 Accepted March 25, 2008

IE800107X 